\title{
Learning Styles and Study Skills among Nursing Students
}

\author{
DONNA LOU E. NERI \\ donnaevasco@yahoo.com \\ Liceo de Cagayan University
}

Date Submitted: June 2007

Final Revision Accepted: October 2007

\begin{abstract}
This study described the learning styles and study skills among Nursing students in five (5) Nursing colleges in Northern Mindanao, namely Liceo de Cagayan University, Central Mindanao University, Mountain View College, Misamis University, and Christ the King College. Kolb's Learning Style Inventory and Study Skills Inventory were used to gather data from the 300 respondents. Data gathered were subjected to descriptive statistics and Pearson Product Moment Correlation Coefficient. The data revealed that the Nursing students have diverging learning style. This learning style is associated with valuing skills, helping others, and sense making. Teaching strategies appropriate for such learning styles must be employed by the faculty to create a match with the students' learning needs. In terms of study skills, the Nursing students are good in note-taking, textbook reading, memory, test preparation, and concentration. However, they are weak in time-management skills. There is a significant relationship between time management skills and Abstract Conceptualization (AC). This underscored the importance of developing time management skills for a student to be able to cultivate his or her critical thinking skills such as synthesis, analysis, and the integration of the concrete experience after reflective observation.
\end{abstract}

Key words - learning styles, study skills, diverging learning style, abstract conceptualization, teaching strategies 


\section{INTRODUCTION}

Baccalaureate nursing program today is becoming more heterogeneous. There is already a mixture of students with increasing number of adults (age 25-50), married and single, male and female, and shiftees and second-coursers who are seeking admission to the Nursing program (Nagata 1996). With this phenomenon, nurse-educators nowadays often find that students are unprepared for the demands of a rigorous Nursing curriculum. Inadequate reading, writing, and study skills hamper their ability to master Nursing and successfully pass the licensure examination (Blowers, Ramsey, Merriman \& Grooms 2003).

Harvey (1995) defines learning styles as those "educational conditions under which a student is most likely to learn." Thus, learning styles are not really concerned with "what" learners learn, but rather "how" they prefer to learn. Learners are helped to succeed in their chosen courses by identifying their preferred learning styles, developing their study skills, and helping them understand how they benefit from various learning materials and activities. Along this insight, the researcher deemed it important to describe the preferred learning styles of Nursing students as well as their study skill for better knowledge acquisition.

Integrating the preferred learning styles of the students into Nursing education program may promote satisfying learning experiences and, at the same time, result in formulation of criteria for academic excellence (Kolb 1984). Moreover, results of Plovnick's research in 1975 (as cited by Nagata 1996) on cognitive theory and occupational roles suggest that people choose fields that are consistent with their learning style and are further shaped to fit the learning norms of their field once they are in it. If a mismatch between an individual's learning style and occupation occurs, the person either changes that style or leaves the field, the latter being more likely.

Kolb (1984) also suggested that different disciplines have inclinntion to different styles of learning. Over time, selection and socialization pressures combine to produce an increasingly impermeable and homogeneous disciplinary culture and correspondingly specialized student orientations to learning. This process, which Kolb calls accentuation, promotes an educational system that emphasizes specialized learning and development through the accentuation of students' skills and interests. Students' developmental pathways are a product of the interaction between their choices and socialization experiences in academic fields and lead them to choose educational experiences that match those 


\section{dispositions.}

Kolb hypothesized that different learning styles may be used to formulate criteria for academic excellence, which in turn may lead to increased productivity in various disciplines. Mismatches between learning style and discipline demands are likely to affect a student's social adaptation to the educational environment and help to explain variations in academic performance. He maintained that there is a strong relationship between how people learn and how they respond to life situations. Performance is limited to short-term adaptations to immediate circumstances, while development is evaluated based on achievement in all life situations (Kolb, 1984). In Kolb's (1984) structure of careers as related to structure of learning knowledge, the discipline of nursing is depicted as an assimilative learning discipline.

Literature has established that both learning styles and study skills influence academic performance. Poor academic performance among nursing students is a common occurrence in the country and even globally. Poor academic performance serves as a predictor on the attrition and employability of students in the future. When students perform poorly in class, the chances are that they will be retained in the program and have difficulty finding work (Stanley, Slate \& Jones 1999). Thus, this study is deemed beneficial to both the nursing students and the Nursing schools in Northern Mindanao. Results of this study can be used as basis in the promotion of appropriate study skills among the students to assist them in coping with the demands of the course, as well as in the development of a curriculum which matches the learning styles of the students.

\section{OBJECTIVES OF THE STUDY}

This study pursued the following objectives: 1) to describe the learning styles of the Nursing students in Northern Mindanao; 2) to determine the study skills of the Nursing students in Northern Mindanao; and 3) to relate learning styles and study skills of Nursing students in Northern Mindanao.

\section{FRAMEWORK}

This study is anchored on Kolb's Learning Style Inventory model. Experiential learning is conceived as a four-stage cycle: (1) immediate concrete experience is the basis for (2) observation and reflection; (3) these observations are assimilated into a "theory" from which new implications for action can be deduced; (4) these implications or hypotheses then serve as guides in acting to create new experiences. The effective learner relies on four different learning modes: Concrete Experience 
(CE), Reflective Observation (RO), Abstract Conceptualization (AC), and Active Experimentation (AE). That is, he must be able to involve himself fully, openly, and without bias in new experiences (CE), he must be able to reflect on and observe these experiences from many perspectives (RO), he must be able to create concepts that integrate his observations into logically sound theories (AC), and he must be able to use these theories to make decisions and solve problems (AE).

A high score on Concrete Experience represents a receptive, experiencebased approach to learning that relies heavily on feeling-based judgments. High CE individuals tend to be empathetic and "people-oriented." They generally find theoretical approaches to be unhelpful and prefer to treat each situation as a unique case. They learn best from specific examples in which they can become involved. Individuals who emphasize Concrete Experience tend to be oriented more towards peers and less toward authority in their approach to learning, and benefit most from feedback and discussion with fellow CE learners. A high score on Abstract Conceptualization indicates an analytical, conceptual approach to learning that relies heavily on logical thinking and rational evaluation. High AC individuals tend to be oriented more towards things and symbols and less towards other people. They learn best in authority-directed, impersonal learning situations that emphasize theory and systematic analysis. They are frustrated by and benefit little form unstructured "discovery" learning approaches like exercises and simulations.

A high score on Active Experimentation indicates an active, "doing" orientation to learning that relies heavily on experimentation. High AE individuals learn best when they can engage in such things as projects, homework, or small group discussions. They dislike passive learning situation such as lectures. These individuals tend to be extroverts. A high score on Reflective Observation indicates a tentative, impartial and reflective approach to learning. High RO individuals rely heavily on careful observation in making judgments and prefer learning situations such as lectures that allow them to take the role of impartial objective observers. These individuals tend to be introverts.

Researches and clinical observations came up with four (4) basic learning style types based on the patterns of LSI scores. The first type is the CONVERGER. The dominant learning abilities of a converger are Abstract Conceptualization (AC) and Active Experimentation (AE). This person's greatest strength lies in the practical application of ideas. A person with this style seems to do best in those situations like conventional intelligence tests where there is a single correct answer or solution to a question or problem. This person's knowledge is organized in such 
a way that through hypothetical-deductive reasoning this person can focus it on specific problems. Research on this style of learning shows that converger's are relatively unemotional, preferring to deal with things rather than people. They tend to have narrow technical interests and choose to specialize in the physical sciences. This learning style is characteristic of many engineers.

The second type is the DIVERGER, who has the opposite learning strengths of the converger. This person is best at Concrete Experience (CE) and Reflective Observation (RO). This person's greatest strength lies in imaginative ability. This person excels in the ability to view concrete situations from many perspectives. $\mathrm{He} / \mathrm{she}$ is labeled as diverger because he/she performs better in situations that call for generation of ideas such as a "brainstorming" idea session. Research shows that divergers are interested in people and tend to be imaginative and emotional. They have broad cultural interests and tend to specialize in the arts. This style is characteristic of individuals from humanities and liberal arts backgrounds. Counselors, organization development specialists, and personnel managers tend to be characterized by this learning style.

The third type is the ASSIMILATOR, with dominant learning abilities of Abstract Conceptualization (AC) and Reflective Observation (RO). This person's greatest strength lies in the ability to create theoretical models. This person excels in inductive reasoning and in assimilating disparate observations into an integrated explanation. This person, like the converger, is less interested in people and more concerned with abstract concepts, but is less concerned with the practical use of theories. For this person, it is more important that the theory be logically sound and precise; in a situation where a theory or plan does not fit the "facts," the assimilator would be likely to disregard or re-examine the facts. As a result, this learning style is more characteristic of the basic sciences and mathematics rather than the applied sciences. In organizations, this learning style is found most often in the research and planning departments.

The last type is the ACCOMMODATOR who has the opposite learning strengths of the assimilator. This person is best at Concrete Experience (CE) and Active Experimentation (AE). This person's greatest strength lies in doing things, in carrying out plans and experiments, and involving oneself in new experiences. This person tends to be more of a risk-taker than people with the other three learning styles. This person is labeled as "accommodator" because this person tends to excel in those situations where one must adapt oneself to specific immediate circumstances. In situations where a theory or plan does not fit the "facts," this person will most likely discard the plan or theory. This person tends to solve problems in an intuitive trial-and-error manner, relying heavily on other people for information rather than on one's own analytic ability. The 
accommodator is at ease with people, but is sometimes seen as impatient and "pushy." This person's educational background is often in technical or practical fields such as business. In organizations, people with this learning style are found in "action-oriented" jobs, often in marketing or sales."

On the other hand, study skills are measured in terms of textbook reading, note-taking, memory, test preparation, concentration, and time management among selected nursing students in Northern Mindanao. The proven technique to sharpen textbook reading skills is the SQ3R which stands for Survey, Question, Read, Recite, Review (Harvey 1995).

In college, students are frequently assigned multiple chapters of course books that can be quite complicated. SQ3R helps make reading purposeful and meaningful, so time is used most effectively. The second study skill investigated is note-taking, which is the practice of writing pieces of information often in an informal or unstructured manner. One major specific type of note taking is the practice of writing in shorthand, which can allow large amounts of information to be put on paper very quickly.

The third variable is the memory, which is crucial to effective use of study skills. The memory system is located in the brain and the brain stem at the top of the spinal cord. The temporal lobes are also involved in registering memories as well as the frontal, parietal, and occipital areas and cerebellum. Memory fails when it does not register something, does not retain over time that which was registered, or fails to remember. Another variable is test preparation that depends on many factors: importance of regular attendance, keeping up with reading assignments, taking notes in class, and doing assignments on time. Each of these contributes toward laying a firm foundation for test preparation. The last variable on the study skills is concentration. Concentration is defined as the ability to direct thinking. The art or practice of concentration is to focus on the task at hand and eliminate distraction. Students have the ability to concentrate sometimes because of worries, outside distractions, and the kind of material they deal with that may be boring, difficult, or uninteresting.

Numerous studies (as cited by Harvey 1995) have had demonstrated the link between study skills and academic success (e.g., GPA) among college students. In terms of the relationship between specific study skills and college achievement, time management has emerged as a predictor of college GPA and quality of academic performance (Britton and Tesser 1991; Macan, Shahani, Dipboye, and Phillips 1990). Moreover, there is a significant relationship between college GPA and students' information processing skills, ability to select main ideas, selftesting, motivation, time management, and concentration. Note-taking has also been found to be related to academic achievement; more specifically, one study 
indicated that the amount of note-taking is positively correlated with performance on tests of lecture material (Kiewra, Benton, and Lewis 1985; Baker and Lombardi 1985). The quality of a student's notes is also related to achievement. Overall, it has been suggested that these and other types of study skills account for approximately $15 \%$ of the variance in the academic achievement of undergraduates.

\section{METHODOLOGY}

This research employed the descriptive-correlational method. The researcher described the learning styles preferred by the Nursing students, their study skills, and the relationship between learning styles and study skills. Specifically, the study was conducted among nursing schools in Northern Mindanao: Liceo de Cagayan University (Cagayan de Oro City), Central Mindanao University (Musuan, Bukidnon), Mountain View College (Valencia, Bukidnon), Misamis University (Ozamiz City, and Christ the King College (Gingoog City). The respondents, who was third and fourth year Nursing students, were selected using the purposive and quota sampling. Sixty (60) students were taken from each school (30 third year and 30 fourth year), hence a total of 300 respondents.

They were requested to answer two standardized questionnaires, the Kolb's Learning Style Inventory and the Study Skills Inventory (Harvey, 1995). Kolb's Learning Style Inventory (LSI) is a self-description test based on experiential learning theory designed to determine the strengths and weaknesses of a learner. The Study Skills Inventory, on the other hand, contains 51 questions divided into the following subscales: textbook reading (8 items), note-taking (5 items), and memory (9 items), and test preparation (13 items), concentration (10 items), and time management (6 items). The rating scale reflects how often items in each subscale are being applied by the respondent as: 5 - almost always, 4 - more than half of the time, 3 - about half of the time, 2 - less than half of the time, and 1 - almost never.

The researcher personally administered the questionnaires. The students were asked to answer the questionnaire as honestly as possible and must not leave any items blank. The data collected were then analyzed using the following statistical tools: the weighted mean for Objective 1 and 2 and Pearson r Product Moment Correlation Analysis at 5\% level of significance for Objective 3.

\section{RESULTS AND DISCUSSION}

The data on students' learning styles revealed that the Nursing students mostly preferred the reflective observation mode of learning. Reflective 
Observation (RO) means taking a time-out from "doing" and stepping back from the task and reviewing things that have been done and experienced. This learning style projects a "passive" nature of the student since there is no actual participation involved.

According to Kolb (1984), a high score on Reflective Observation (RO) is indicative of an impartial and reflective approach to learning. High RO individuals rely greatly on careful observation before making any judgments. They also like learning situations such as lectures which allow them to be neutral objective observers. In the Nursing, the teaching strategy being used most often is lecture since there is a large amount of information to be taught to the students with very limited time. From this realization, it can be said that the lecture-type of teaching may just be an appropriate strategy among these group of nursing students with high RO.

The second preferred learning style was Concrete Experience (CE). A high score on Concrete Experience (CE) represents a receptive, experience-based approach to learning that relies heavily on feeling-based judgments. High CE individuals are more likely to be empathetic and are "people-oriented". They find theoretical approaches unhelpful and prefer to take each situation as a unique case. They learn best from specific examples in which they can become involved. Individuals with high CE tend to be peer-oriented rather than authority-oriented. They often learn more from giving feedback and having discussion with fellow CE learners.

Furthermore, the highest mean in CE among the Nursing students was learning through hands-on experience had the highest mean while learning effectively from peers had the lowest mean. "Hands-on activities mean students have objects (both living and inanimate) directly available for investigation". Other terms for hands-on activities are materials-centered activities, manipulative activities, and practical activities. In the Nursing curriculum, starting from the second year, students are already exposed to actual healthcare settings. They spend about 50 percent of their time in clinical duties, otherwise termed as related learning experiences (RLE). 
Table 1. Learning styles of nursing students in Region 10

\begin{tabular}{|c|c|c|}
\hline Concrete Experience & Mean & Verbal description \\
\hline I prefer hands-on learning experience. & 3.26 & Always \\
\hline I tend to rely on feelings when making decisions. & 2.98 & Almost Always \\
\hline I learn more effectively from my peers. & 2.96 & Almost Always \\
\hline I like learning through simulations. & 3.09 & Almost Always \\
\hline I learn well by practical experience. & 3.00 & Almost Always \\
\hline Overall Mean & 3.05 & Almost Always \\
\hline Reflective Observation & & Almost Always \\
\hline I learn best through observation. & 3.13 & Almost Always \\
\hline I would rather read about disadvantaged youth. & 3.24 & Almost Always \\
\hline I prefer assignments that require me to think about situations. & 3.08 & Almost Always \\
\hline I learn well through listening to what others have to say. & 3.18 & Almost Always \\
\hline I tend to think about possible outcomes before trying something new. & 2.93 & Almost Always \\
\hline Overall Mean & 3.11 & Almost Always \\
\hline Abstract Conceptualization & & Almost Always \\
\hline I prefer learning through thinking and reasoning & 3.05 & Almost Always \\
\hline I tend to rely on logical reasoning when making decisions & 3.04 & Almost Always \\
\hline I learn more effectively from my teachers & 3.13 & Almost Always \\
\hline I like learning through lectures & 3.05 & Almost Always \\
\hline I tend to think about possible outcomes before trying something new. & 2.93 & Almost Always \\
\hline Overall Mean & 3.03 & Almost Always \\
\hline Active Experimentation & & Almost Always \\
\hline I learn best through active involvement in projects & 3.05 & Almost Always \\
\hline I would rather do volunteer work with disadvantaged youth & 3.09 & Almost Always \\
\hline I prefer assignments that require me to work examples & 2.98 & Almost Always \\
\hline I learn well through participating in discussions & 2.98 & Almost Always \\
\hline I tend to jump right in and do something new & 2.89 & Almost Always \\
\hline Overall Mean & 2.99 & Almost Always \\
\hline
\end{tabular}

Interpretation: 1.00-1.74 - Never; 1.75-2.49 - Sometimes; 2.50-3.24 - Almost always; 3.25-4.00- Always

From the follow-up interview conducted, the students showed preference for teaching strategies that are designed to be touched or handled and that develop their muscles, perceptual skills, psychomotor skills, etc... They also value their peers as a source of knowledge. In many cases, they regard them as a learning resource that is more useful than book learning or laboratory exercises.

The topmost preferred learning styles among the respondents were Reflective Observation (OR) and Concrete Experience (CE). The combination of the two, however, describes the DIVERGER style of learning (Kolb, 1984). Individuals with diverging style are best at viewing concrete situations from many different points of view. According to the profile, these are people who have broad cultural interests and like to gather information. They are interested in people and tend to be imaginative and emotional. They also tend to specialize in the arts. This finding is quite consoling as nursing has long been viewed as an art, the art of taking care of both the well and the sick (Kozier \& Erb 2004).

As expected in a human service profession, nursing learning environments have been found to have a predominantly concrete learning press, matching the predominating concrete styles of nurses. This finding is consistent with the study 
of Nagata (1996). On the contrary, the learning styles least preferred by the Nursing students were the Abstract Conceptualization (AC) and Active Experimentation (AE). In combination, these two learning preferences (AC and AE) give birth to a CONVERGER (Kolb, 1984). Convergers' are described as relatively unemotional, who prefer to deal with things rather than people. They tend to have narrow technical interests and choose to specialize in physical sciences. This learning style is characteristic of many engineers. This is another reassuring finding as no client or patient would want to have a nurse who is a converger. The Nursing profession is for individuals with "big" hearts since TLC (tender loving care) is a must for a nurse to possess.

Objective 2 of this study sought to determine the study skills among nursing students in Northern Mindanao. The data show that the Nursing students were good at note-taking. They specifically take note during lectures and when they read textbooks. They likewise compare notes with their classmates to check on completeness and accuracy. However, they no longer rewrite lecture notes because, according to them, they do not have the time to do so.

Moreover, the Nursing students also did well in test preparation, memory, concentration, and textbook reading. Nevertheless, there were some study skills that need to be improved. These shills are highlighted in Table 2. The area in which the Nursing students were least skillful was on time management. Specifically, they generally need to be taught on making a calendar/schedule of daily, weekly, or monthly activities so they can prepare well for other academic or personal activities. Also, they usually do not have short-or long-term goals to help those set priorities. Since the Nursing program involves a lot of subjects with theory and clinical teaching conducted in simulation, proper management of time is very important. Poor time management is sometimes the cause of students' academic failure. Hence, nursing students must be adequately armed with time management skills for them to cope with the demands of the course.

Table 2. Study skills of selected nursing students in Region 10

\begin{tabular}{lll}
\hline \multicolumn{1}{c}{ Textbook reading skills } & Mean & Verbal description \\
\hline I formulate questions from a chapter before I begin reading. & 3.36 & About half of the time \\
I try to get the meaning of words before reading an assignment, I survey & 3.57 & More than half of the time \\
headings, bold print, summaries, etc. & 3.64 & More than half of the time \\
I try to get the meaning of new term as I encounter them the first time. & 3.37 & About half of the time \\
I formulate questions to answer as I read an assignment & 3.57 & More than half of the time \\
I look for main ideas as read. & 3.46 & More than half of the time \\
I am able to readily identify clarifying details under each main idea & 3.41 & More than half of the time \\
I read a textbook chapter more than once. & 3.37 & About half of the time \\
I use a textbook study system such as SQ3R. & 3.51 & More than half of the time \\
Note taking skills & 3.94 & More than half of the time \\
I take notes as I read my textbook assignments. & 3.63 & More than half of the time \\
I take notes in lectures. & &
\end{tabular}


(Table 2. Continued)

Textbook reading skills accuracy.

Overall Mean

Memory

I review notes more than once or twice for exams and quizzes

I use mnemonics.

I use visuals in my notes such as sketches, mind maps, diagram, charts, etc.

I quiz myself over material that could appear on future exams and quizzes.

I organize details to main ideas into numbered or lettered lists.

I convert text and lecture material into my own words

I think about material that could be on exams and quizzes when I am not studying.

I try to understand material in my notes as opposed to memorizing.

I try to organize main ideas and details into some logical or meaningful order.

Overall Mean

Test preparation

I study with a classmate or group.

When I don't understand something, I get help from classmates, tutors, instructors, etc.

I do all homework assignments.

I turn in all homework assignment on time

I can easily identify what I have learned and what I have not yet learned before I take a test.

I review notes for a class before I go to that class.

I read assigned material before I go to class

I begin studying for an exam from the first week material is assigned or covered in lecture

I review lecture notes soon after class.

I keep up to date on assignments and homework.

I eat well-balanced meals daily.

I exercise daily.

I have taken a learning skills class or attended learning skills workshops.

\section{Overall Mean}

\section{Concentration}

I study when it is quiet when trying to learn and remember something

I study for a length of time then take a short break before returning to

studying.

I study in the same place.

I avoid cramming.

I have all my study equipment handy to my study place (pens, paper, calculator. etc.).

When I sit down to study, I tell myself that I intend to study.

I break larger tasks into smaller segments in order to complete a large assignment.

When the subject matter is not naturally interesting. I find ways to learn it anyway.

It is not difficult to pay attention in class.

I avoid studying in the evenings as much as possible.
Mean Verbal description
3.63

3.64

3.55

3.45

3.51

3.54

3.38

3.54

3.48

3.46

3.76

3.70

3.75

3.57

3.28

3.53

3.31

3.35

3.61

3.76

3.38

3.16

3.51

3.50

3.33

3.51

3.58

3.46

3.58

3.40

3.25

3.47
More than half of the time

More than half of the time

More than half of the time More than half of the time More than half of the time More than half of the time More than half of the time About half of the time More than half of the time

More than half of the time More than half of the time

More than half of the time

More than half of the time More than half of the time

More than half of the time More than half of the time More than half of the time

About half of the time More than half of the time About half of the time

About half of the time More than half of the time More than half of the time

About half of the time About half of the time

More than half of the time

More than half of the time More than half of the time

More than half of the time About half of the time More than half of the time

More than half of the time More than half of the time

More than half of the time

More than half of the time About half of the time

Overall Mean 
As to the relationship between learning styles and study skills among the Nursing students, only one significant relationship existed and it was between time-management skills and Abstract Conceptualization (AC), P-value (0.029) < the alpha (0.05). Abstract Conceptualization (AC) involves synthesis, analysis, and the integration of the concrete experience after reflective observation into new theories. Students are involved with abstract conceptualization in lectures, papers, projects, and analogies (Gadzella \& Williamson 1984). These critical thinking activities entail effective time management skills. Becoming involved in the critical thinking process is more than cognitive activities such as logical reasoning or scrutinizing arguments for assertions unsupported by empirical evidence. Thinking critically involves recognizing the assumptions underlying beliefs and behaviors. It means justifications for ideas and actions could be given. Most importantly, it means judging the rationality of these justifications. Thinking through, projecting, and anticipating the consequences of those actions need to be done with careful time management (Gleason, Archer \& Colvin 2002; Elliot, Mc Gregor \& Gable 1999).

It is vital for nurses to develop Abstract Conceptualization (AC) since they are dealing with human lives. Professional nurses must be able to develop critical thinking skills to make sound judgments and provide the safest and best care for their patients in everyday nursing practice (Mouw \& Khanna 1993). The findings of this study confirm that having time management skills influences the development of Abstract Conceptualization (AC) among nurses.

\section{CONCLUSIONS}

The nursing students have DIVERGING learning style. This learning style is associated with valuing skills, helping others, and sense making. Teaching strategies appropriate for such learning style must be employed by the faculty to create a match with the students' learning needs.

The Nursing students have good study skills such as note-taking, textbook reading, memory, test preparation, and concentration. However, they are having poor time-management skills. The items highlighted in Table 2 can help in the development of a Study Skills Training for nursing students.

Time management skills influence the enhancement of Abstract Conceptualization (AC) among nursing students. If student nurses can manage their time wisely, they have the time to think critically and rationally. 


\section{LITERATURE CITED}

Baker, L., \& Lombardi, B. R. (1985). Students' lecture notes and their relation to test performance. Teaching of Psychology, 12(1), 28-32.

Blowers, S., Ramsey, P. Merriman, C. \& Grooms, J. (2003). Patterns of peer tutoring in nursing. Journal of Nursing Education, 42 (5) 204-211.

Britton, B. K., \& Tesser, A. (1991). Effects of time-management practices on college grades. Journal of Educational Psychology, 83(3), 405-410.

Elliott, A. J., McGregor, H. A., \& Gable, S. (1999). Achievement goals, study strategies, and exam performance: a mediational analysis. Journal of Educational Psychology, 91(3), 549-563.

Gadzella, B. M., \& Williamson, J. D. (1984). Study skills, self-concept, and academic achievement. Psychological Reports, 54, 923-929.

Gleason, M. M., Archer, A. L., \& Colvin, G. (2002). Interventions for improving study skills. In M. R. Shinn, H. M. Walker, \& G. Stoner (Eds.), Interventions for academic and behavior problems II: preventive and remedial approaches (pp. 651680). Washington, D.C.: National Association of School Psychologists.

Harvey, V. S. (1995). Teaching study skills. In A. Thomas \& J. Grimes (Eds.), Best practices in school psychology (third ed., pp. 931-942). Washington, DC: National Association of School Psychologists.

Kiewra, K. A., Benton, S. L., \& Lewis, L. B. (1985). Qualitative aspects of note taking and their relationship with information-processing ability and academic achievement. Journal of Instructional Psychology, 14(3), 110-117.

Kolb, D. (1984). Learning style inventory. Boston, MA:Mcber and Company.

Kozier, B. and Erb, G. (2004). Fundamentals in nursing. Philadelphia: Lippincott Publishing.

Macan, T. H., Shahani, C., Dipboye, R. L., \& Phillips, A. P. (1990). College students. Time management: correlations with academic performance and stress. Journal of Educational Psychology, 82(4), 760-768.

Mouw, J. T., \& Khanna, R. K. (1993). Prediction of academic success: a review of the literature and some recommendations. College Student Journal, 27(3), 328336.

Nagata, B.J. (1996). Students' academic performance in nursing as a function of student and faculty learning style congruency. Journal of Nursing Education. v35. p69-73.

Stanley, B., Slate, J.R. and Jones, C.H. (1999). Study behaviors of college preparatory and honors students in the ninth grade. The High School Journal. 82 (3) $165-171$. 